\title{
Analysis of the Optimization on Application of Seawater Slurry Ice in Coastal Areas
}

\author{
Yunrui Fang ${ }^{1}$, Linhui Hua ${ }^{1}$, ChengKun $\mathrm{Jin}^{2}$, Junkai Gao ${ }^{1}$, and Zhi Han ${ }^{1 *}$ \\ ${ }^{1}$ School of Naval Architecture and Maritime, Zhejiang Ocean University, Zhoushan, Zhejiang, 316000, China \\ ${ }^{2}$ School of Foreign Languages, Zhejiang Ocean University, Zhoushan, Zhejiang, 316000, China
}

\begin{abstract}
Cold Storage is a key point of cold chain logistics. In this article, the cooling capacities of water, slurry ice and seawater slurry ice were compared, and results showed that both slurry ice performed better than water. Furthermore, differences between seawater ice and slurry ice were analyzed, and experimental results showed that seawater ice has more advantages as coolant for cold storage in the coastal areas. On the basis of the study, we put forward a new design of high temperature cold storage for coastal areas (inland cities).
\end{abstract}

\section{Introduction}

Cold Storage refers to a warehouse that uses cooling facilities to create an environment with proper levels of humidity and low temperature [1]. High temperature cold storage above $-5^{\circ} \mathrm{C}$ plays a vital role in the logistics chain [2], and the room temperature requirement varies generally from $0^{\circ} \mathrm{C}$ to $4{ }^{\circ} \mathrm{C}$. Currently, high temperature cold storage is mainly used for preservation of fresh eggs, fruit and vegetables, water colors, flowers, Chinese herbal medicines, and commodities such as high-end furniture and clothing. In China, high-temperature cold storage is most widely used in the preservation of fruits, vegetables and eggs, and mechanical refrigeration and controlled atmosphere storage are two commonly used storage and preservation technologies in fruits and vegetables preservation [3]. Controlled atmosphere storage can offer excellent preservation effect, but when applied to preservation of fruits, vegetables and eggs, economic benefits fail to meet the needs of relevant agricultural practitioners owing to its high cost. As for mechanical refrigeration, cold source mainly comes from inexpensive cold water; however, conveying power consumption is incurred due to large demand.

Ice slurry is a new type of storage medium with better cooling storage properties than water. Its application in high temperature cold storage enjoyed extensive attention thanks to its superior heat transfer performance. Research shows that the heat transfer rate of plate heat exchanger with ice slurry as coolant is more than three times higher than that of water [4]. The use of ice slurry for refrigeration and preservation has been an emerging research direction in recent years. Seawater ice slurry has better performance compared to ice slurry, and has wider application prospects in coastal areas (or island cities) where seawater is easily accessible. This paper aims to study the application of seawater to produce slurry ice in high temperature cold storage in coastal areas (or island cities).

\section{Application of Seawater Slurry Ice in High Temperature Cold Storage}

\subsection{Seawater Slurry Ice}

Ice slurry, also recognized as ice slurry and pumpable ice, is a kind of two-phase solution containing suspended ice particle with diameter less than $1 \mathrm{~mm}$ (typically 0.1 to 1 $\mathrm{mm}$ in diameter), the cool storage capacity of ice and the liquidity of aqueous solution [5]. Compared with traditional counterparts, ice slurry has a higher ice storage density and better refrigeration performance. Ice slurry is composed of ice particles and therefore has a large surface area, which allows it to cool quickly; and compared with water and other single-phase liquids, it can also use phase change heat to maintain low temperature for a longer period in the cooling process [6].

There are pure water ice slurry and binary ice containing binary solution, both of which are produced by means of dynamic ice-making method based on cooling heat transfer mechanism. By dissolving additives, binary ice can change the phase transformation temperature of aqueous solution, the morphology of ice particles and even the physical properties of ice slurry. These additives are often referred to as 'freezing point depressants' in crystallization theory, including inorganic salts (sodium chloride, potassium chloride, etc.) [7] and low molecular organic substances that are highly soluble in water (ethanol, ethylene glycol, propanol, vinyl alcohol, silane coupling agents, triglycerides, etc.) [8]. Compared with pure water slurry ice, slurry ice produced by solution containing freezing point depressants has better fluidity. In fact, sea-slurry ice is actually a binary fluid ice containing sodium chloride additives. 


\subsection{Design of High Temperature Cold Storage Using Seawater Ice Slurry}

In refrigeration cycle, ice slurry is used as cold source in place of ordinary cold water, and scraping ice slurry maker is used as fluidized ice generator. Indirect refrigeration is an effective way to optimize the safety control of ammonia cold storage, separating the cold store from the refrigeration system with a view to reducing the probability of ammonia leaks in low-temperature cold storage. On the basis of the notion, separate high temperature cold storage is designed as illustrated in Fig 1.

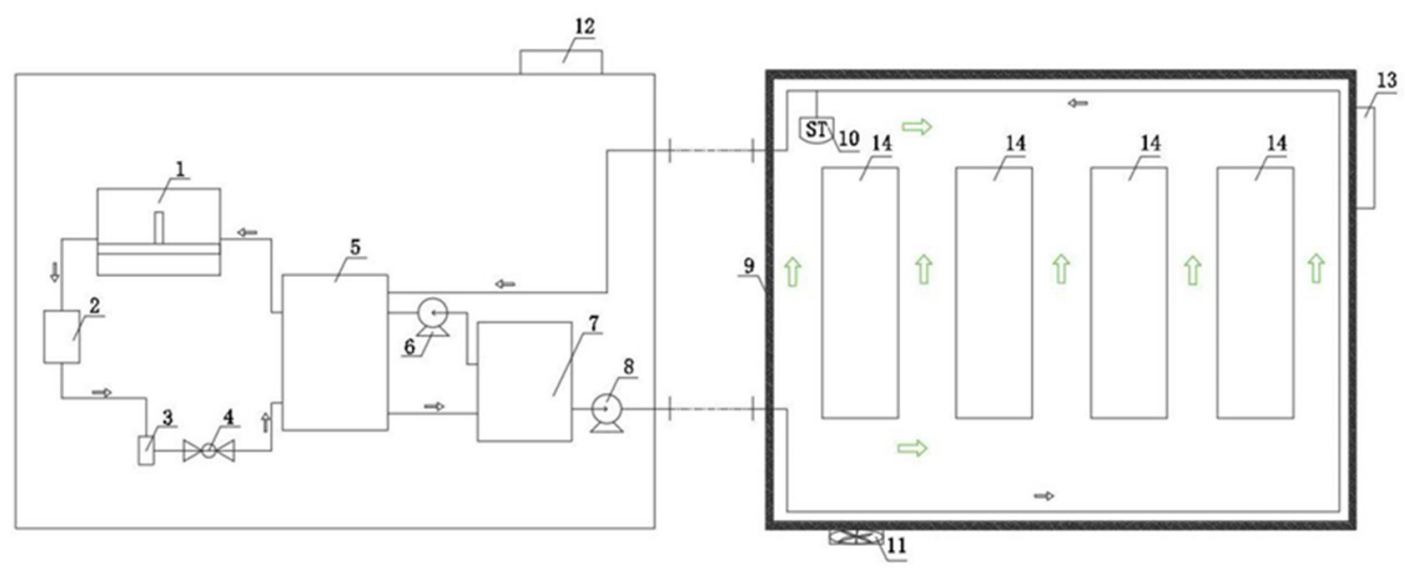

1.Compressor; 2. Air-cooled condenser; 3. Expansion valve; 4. Accumulator; 5.Fluidized Ice Generator; 6. Circulation pump; 7. Ice storage tank; 8. Output pump; 9.Insulation layer; 10. Temperature sensor; 11. Fan system; 12. Machine room gate; 13 . Cold storage gate; 14 . Goods shelves;

Fig 1. Separated high temperature cold storage system.

Separate high temperature cold storage system is composed of a machine room and cold storage. Ice slurry is produced in the fluidized ice generator in the machine room and then flows into the ice storage pond via the outlet. In cooling process, ice slurry in ice storage pond returns to cold storage through export pump for heat exchange, after which the ice slurry melts into lowtemperature brine solution and returns to fluidized ice generator for ice slurry production. There are two closed circles in the single high-temperature cold storage system, i.e., refrigerant circle and ice-making solution circle, the operation of which is described as follows.

Refrigerant circle: A certain amount of seawater or salt solution with certain salinity is introduced into the ice storage tank, and the solution is pumped to the top of the fluidized ice generator through a circulation pump to produce slurry ice. Then ice crystals are mixed with the low-temperature ice-making solution and then flow back to the ice storage tank through the outlet of the generator.

Ice-making solution circle: The refrigerant is compressed by compressor into high temperature and high pressure gas refrigerant and is discharged through the exhaust port of the compressor into the air-cooled condenser, transferring the heat of the refrigerant to the air. Then the high-temperature refrigerant enters the accumulator and passes through the fluidized ice generator for heat exchange after being depressurized by thermal expansion valve to low-temperature and low pressure state. The refrigerant is vaporized and sucked up by the compressor to form a cycle.

\section{Comparison of Cooling Capacity}

Cooling capacity is an important indicator to evaluate refrigerants, and also an advantage of ice slurry in comparison with water. Therefore, the analysis of the cooling capacity of water, slurry ice and sea-water ice are helpful to the overall understanding of the three refrigerants. Water provides cooling through sensible heat without phase transition. When slurry ice is cooled, it can not only provide cold energy through sensible heat of ice and current-carrying solution, but also release a large amount of cold energy through latent heat of phase change of ice. According to the cooling characteristics of slurry ice, the cooling capacity (KW) is expressed by the amount of fluid ice content transported in the pipeline per unit time by using the following equation:

$$
\mathrm{Q}=\mathrm{V} \times \mathrm{A} \times \rho \times\left[\mathrm{X}_{\mathrm{S}} \times\left(\mathrm{r}+\mathrm{c}_{1} \times \mathrm{T}_{0}\right)+\mathrm{c}_{2} \times \mathrm{T}\right]
$$

where $\mathrm{v}(\mathrm{m} / \mathrm{s})$ is the velocity of fluid transport in the pipeline, $\mathrm{A}$ is the floor area of the pipeline $\left(\mathrm{m}^{2}\right), \rho\left(\mathrm{kg} / \mathrm{m}^{3}\right)$ is the density of fluid $(\mathrm{Kg} / \mathrm{m}), \mathrm{r}(\mathrm{KJ} / \mathrm{kg})$ is the latent heat of ice melting, $\mathrm{Xs}(\%)$ is the ice content of the slurry ice, which is 0 when the refrigerant is water, and $\mathrm{c}_{1}\left(\mathrm{KJ} / \mathrm{kg} \cdot{ }^{\circ} \mathrm{C}\right)$ is the specific heat of the ice at constant pressure; $\mathrm{c}_{2}\left(\mathrm{KJ} / \mathrm{kg} \cdot{ }^{\circ} \mathrm{C}\right)$ is the constant pressure specific heat of solution, $\mathrm{T}_{0}\left({ }^{\circ} \mathrm{C}\right)$ is the absolute value of the initial temperature of the refrigerant entering the pipe heat exchanger, $\mathrm{T}\left({ }^{\circ} \mathrm{C}\right)$ is the temperature of the refrigerant leaving the pipe heat exchanger. 


\subsection{Design Parameters}

The densities of ice and water are taken to be $916.8 \mathrm{~kg} / \mathrm{m}^{3}$ and $999.84 \mathrm{~kg} / \mathrm{m}^{3}[9]$ respectively. The average salinity of seawater is specified as $3.5 \%$ and the density of lowtemperature seawater is estimated to be $1026.5 \mathrm{~kg} / \mathrm{m}^{3}$ based on the formula for the density of brine solutions [10]. The latent heat of cold content is $335 \mathrm{KJ} / \mathrm{kg}[11]$. The specific heat of ice is $2.1 \mathrm{KJ} / \mathrm{kg} \cdot{ }^{\circ} \mathrm{C}$, the specific heat of water is $4.2 \mathrm{KJ} / \mathrm{kg} \cdot{ }^{\circ} \mathrm{C}$ and the specific heat of seawater is $4 \mathrm{KJ} / \mathrm{kg} \cdot{ }^{\circ} \mathrm{C}[12]$. Other parameters are related to calculations and relevant papers.

\subsubsection{Pipe diameter}

In the choice of pipe diameter, resource conservation, reduction of refrigerant charge and optimization of refrigeration system should be taken into account. Liu Jing et al [13] calculated that the pipe diameter of the liquid refrigerant cooling pipe is $31.3 \mathrm{~mm}$, and in this paper an approximate diameter of $30 \mathrm{~mm}$ is adapted.

\subsubsection{Ice content}

The latent heat of phase change of ice accounts for the better refrigeration efficiency of slurry ice than that of water. The higher the ice content is, the greater the cooling capacity of slurry ice will be. However, high ice content leads to the increase of the flow resistance and thus influences the fluidity of slurry ice. Therefore, both fluidity and refrigeration efficiency should be considered in quest of the optimum ice content.

Mingang's research showed [14] that the resistance of slurry ice decreases as the ice content increases from 3.5\% to $14 \%$, and is less than that of water; the resistance of slurry ice increases as the ice content increases from $22 \%$ to $29.5 \%$, and is greater than that of water. Besides, the ice content of slurry ice under $30 \%$ is in safe working condition [15]. In this paper, slurry ice with ice content of $5 \%, 10 \%, 15 \%, 20 \%$ and $25 \%$ has been chosen as coolant.

\subsubsection{Density}

Since densities of the solid phase and liquid phase show little difference, and solid particles represent the second phase, the density of ice slurry can be measured by linear weighted calculation, as shown in the following expression 16:

$$
\rho=\left(X_{S} / \rho_{1}+\left(1-X_{S}\right) / \rho_{2}\right)^{-1}
$$

where $\rho_{1}$ is the density of ice particles, $\rho_{2}$ is the density of solution, and $\mathrm{X}_{\mathrm{s}}$ is the ice content. As such, the density of slurry ice and sea-water ice can be obtained.

\subsubsection{Flow Velocity}

Critical flow velocity refers to the velocity of slurry in uniform or non-suspension state passing through pipes with given transport concentration and diameter. The actual flow velocity of slurry should exceed the critical flow velocity by $0.3 \mathrm{~m} / \mathrm{s} 17$. The critical velocity vc $(\mathrm{m} / \mathrm{s})$ of slurry ice can be written as 18 :

$$
\mathrm{v}_{\mathrm{c}}=0.85\left[0.35+1.36^{3}\left(\mathrm{C}_{\mathrm{w}} \mathrm{D}^{2}\right)^{\frac{1}{2}}\right] \beta
$$

$\mathrm{C}_{\mathrm{w}}$ is mass consistency, $\mathrm{D}(\mathrm{m})$ is pipe diameter, $\beta$ is density correction factor which could not be considered in ice particles. This then gives the mass consistency as:

$$
\mathrm{C}_{\mathrm{w}}=\rho_{1}\left(\rho^{-} \rho_{2}\right) \quad\left[\rho_{2}\left(\rho_{1}-\rho\right)\right]^{-1}
$$

where $\rho_{1}\left(\mathrm{~kg} / \mathrm{m}^{3}\right)$ is the density of ice particles, $\rho_{2}(\mathrm{~kg} / \mathrm{m}$ ${ }^{3}$ ) is the density of solution. The critical velocity of slurry ice and seawater ice has been worked out with above formulas and parameters as approximately $0.3 \mathrm{~m} / \mathrm{s}$. Therefore, in this essay, actual velocity of ice slurry is specified as $0.6 \mathrm{~m} / \mathrm{s}$.

\subsubsection{Temperature}

Huang Cheng et al.[19] studied the relationship between the outlet temperature of liquid ice and the type and concentration of additive solutions in ice making, and concluded that the temperature of slurry ice made from $3.5 \%$ sodium chloride solution should be between $-1.34^{\circ} \mathrm{C}$ and $-1.94^{\circ} \mathrm{C}$. Therefore, the initial temperature of sea water ice is specified as approximately $-1.64^{\circ} \mathrm{C}$. Besides, pure water slurry ice is by nature the best constant temperature cold source[20], so we take the initial temperature of slurry ice made from pure water and that of water as $0^{\circ} \mathrm{C}$. According to room temperature of the common high temperature cold storage, the temperature of the refrigerant after heat transfer is specified as $4^{\circ} \mathrm{C}$.

\subsection{Analysis of the Results}

The results of the ice content of water, slurry ice and seawater ice obtained from above-mentioned formulas and parameters are shown of Fig.2. 


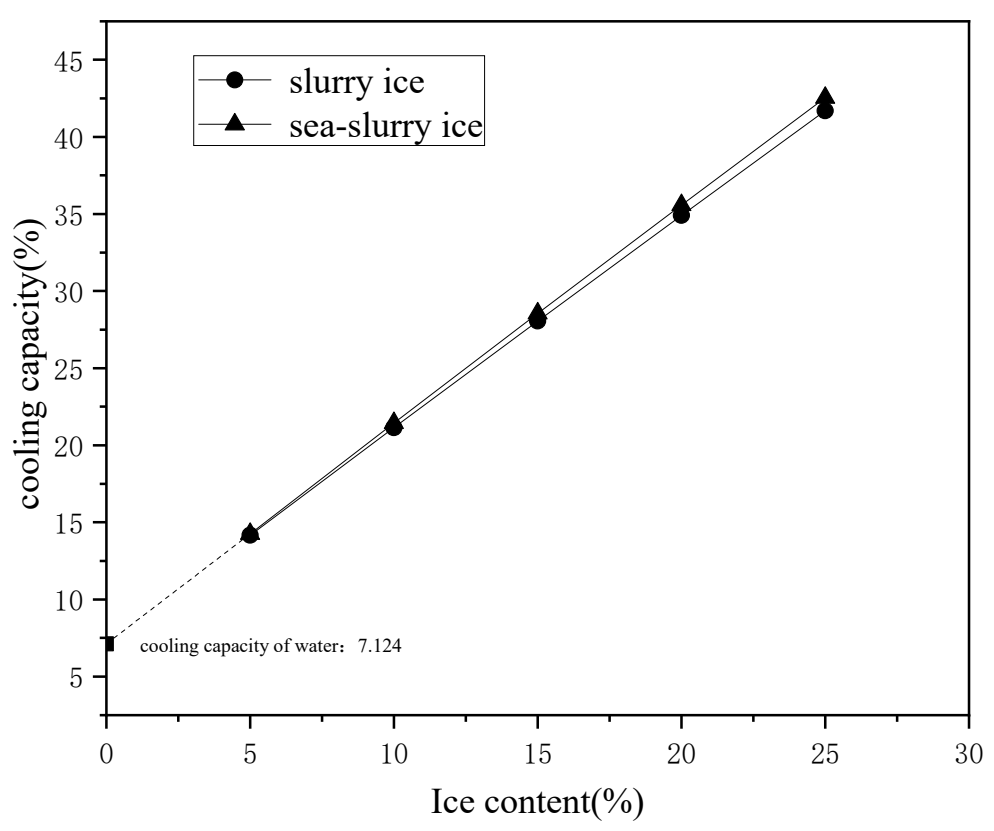

Fig 2. Comparison of cooling capacity of refrigerant carrier.

As can be seen from the figure, the cooling capacity of the two kinds of slurry ice increases with the rise of ice content, and the cooling capacity of seawater ice always slightly higher than that of slurry ice with the same ice content, both of which are obviously higher than that of water. Ice transport of slurry ice with $5 \%$ and $25 \%$ ice content is about 2 and 6 times that of water respectively. In addition, slurry ice with 5\% ice content occupies $50 \%$ of space occupied by water, and slurry ice with $25 \%$ ice content only $17 \%$. These mean that in operation, cold storage using water as coolant requires pipes with larger diameter, which demonstrates that using slurry ice as a coolant has obvious advantages with regard to cost and refrigeration.

Apart from differences in cooling capacity, there are differences with respect to fluidity and energy consumption. In microscopic observation, the ice crystals of slurry ice made of pure water are dendritic-like particles with rough and elongated surfaces, which easily entangle and cluster and lead to blockage. While slurry ice crystals prepared by the solution containing freezing point depressant are smooth and small spheres, which remarkably reduce the energy loss engendered by friction between crystal particles and are less likely to cause blockage in transportation[21][22]. Thus, seawater ice has better fluidity than slurry ice. Zhang Roujia's experiment[23] showed that the subcooling degree of seawater and pure water in constant water bath environment at $-10.0^{\circ} \mathrm{C}$ was $7.1^{\circ} \mathrm{C}$ and $8.2^{\circ} \mathrm{C}$ respectively when the initial temperature was $10.0^{\circ} \mathrm{c}$. It was shown that the subcooling degree of seawater is lower, which helps reduce energy consumption in ice making.

\section{Conclusion}

In comparison with high temperature cold storage using water as coolants, the application of slurry ice considerably reduces the size of tanks, pumps, pipes, and coolers due to high energy density and pumpability of slurry ice. Despite that the cooling capacity of seawater ice and slurry ice at the same level of ice content shows no distinct difference, application of seawater ice in coastal areas (or island cities) is more practical considering its abundance and superiority in terms of low energy consumption and better fluidity than slurry ice in ice production. However, corrosion inhibitor should be utilized in cold storage to counteract seawater corrosion. Corrosion inhibitor is widely used and developed in corrosion resistance in petrochemical equipment[24], thus impacts on operating costs of high-temperature cold storage using seawater ice are not significant thanks to its affordable price and easy operation.

The high-temperature cold storage design proposed in this essay remains applicable to inland areas where seawater is not easily available. To be specific, saltwater slurry ice generated by sodium chloride solution with certain concentration can be used as the cold source in cold storage. To meet practical needs, the physical properties of the slurry ice can be changed by adjusting the concentration of the solution. Nonetheless, the specific effects of different concentrations of sodium chloride solutions on the physical and chemical properties of slurry ice are subject to further research.

\section{Acknowledgements}

The authors are grateful for the financial supports of the National Sparking Plan Project (No. 2013GA700254), Zhejiang Provincial Public Projects of China (No. 2017C31008), Science and Technology Planning Project of Zhoushan of China (No. 2016C41004), Science and technology innovation program for college students in Zhejiang province of China(2016R411025). 


\section{References}

1. Sun, J.Z. (2017) Discuss on the Design and Develop of Thermal Insulation System on Cold Store Construction. J. Logistics Engineering and Management, 39(10): 76-79.

2. Xun, L.Q. (2020) 2019 China Analysis on Air Cooler Product Market. J. Chinese Journal of Refrigeration Technology, 40(S1): 60-67.

3. Zhang, Y. (2017) The design of natural cold source of preservation system for preservation storage. D. Shenyang Agricultural University.

4. FERNANDEZ, S.J., DIZ, R. (2014) Thermohydraulic behavior of ice slurry in an offset strip-fin plate heat exch anger.J. International Journal of Refrigeration, 41 (5) :171-180.

5. Ma, Q.W. (2020) Research on ice making performance and equipment optimization of ice slurry maker for fishing boat. D. Zhejiang Ocean University

6. Gao, M., Zhang, B., Deng, S.G., Aubourg, S. (2014) Using and Development of Ice Slurry Preservation in Food Industry. J. The Food Industry., 35(02): 178182.

7. KAUFFELD, M., CHRISTENSEN.K.G., LUND.S.(1999) Experience with ice slurry. In: Proceedings of the First Workshop on Ice Slurries of the International Institute of Refrigeration. Switzerland.pp.42-73.

8. INADA, T., LU, S.S., GRANDUM, S. (2000) Microscale analysis of effective additives for inhibiting recrystallization in ice slurries. In: 2nd Workshop on Ice Slurries of the International Institute of Refrigeration. Paris. pp. 84-91.

9. Liu, G.Q. (2002) Data book of chemical and chemical properties. Chemical Industry Press, Beijing.

10. Zeng, Q.S. (1994) Density formula of salt aqueous solution. J. Chemical Engineering Design, 05:35$36+9$.

11. Liu, Z.B., Wu, R.H., Yu, H. (2019) Operation test for heat pump heating system using latent heat of water transformation. J. Heating Ventilating \& Air Conditioning, 49(01): 96-100.

12. Wang, F., Zhang, R.Y., Li, H.Z. (2016) Research on the characteristics of water drenching fillers of seawater cooling tower in nuclear power station. J. Water \& Wastewater Engineering,52(02):60-64.

13. Liu, J., Chen, S.S., Du, Z. (2014) The application research on new cooling transmission system in a mine air conditioning. J. Shanxi Architecture, 40(36): 118-119.

14. Ming, G., Chen, P.L.(1999) Experimental study on flow and heat transfer characteristics of ice slurry in horizontal tube. In: 1999 annual meeting of Shanghai Refrigeration Society.Shanghai.pp.375-378.

15. Zhang, X.Y. (2009) Reasech on Key Technologies of Cooling Source of Mine Cooling System for Ultradeep Mines. D. Wuhan University Of Technology.
16. Jian, X.Z. (2008) A Study of the Flow and Heat Transfer Characteristics of Binary Ice Slurry. D. Nanjing University of Aeronautics and Astronautics.

17. Wang, S.Z. (2004) Pipeline transportation engineering. Mechanical Engineering Press, Beijing.

18. Tong, Q.L. (1982) Theoretical basis of two phase flow. Metallurgical Industry Press, Beijing.

19. Huang, C., Liu, X., Lin, S., Liu, J.J., Tang, Y.J., Li, X.L. (2017) Influence of Solution Properties on the Ice Slurry Product by Spiral Scraping Typ.J. The Chinese Journal of Process Engineering, 17(03):520525.

20. Song, W.J., Feng, Z.P., Xiao, R. (2019) Progress of Ice Slurry Technology and Its Prosperity Applications. J. Advances in New and Renewable Energy, 7(02): 129-141.

21. KASZA, K., HAYASHI, K. (2001) A method for measuring ice particle slurry agglomeration in storage tanks. J. ASHRAE Transactions, 106 (Pt. 1): 117-123.

22. KAUFFELD, M., KAWAJI, M., Egolf, P.W. (2005) Handbook on Ice Slurriese Fundamentals and Engineering. IIF/IIR, Paris.

23. Zhang, R.J. (2014) Research on the energy-saving in process of making seawater slurry ice on fishing vessel using nucleating agent.D. Zhejiang Ocean University.

24. Ma, W.L., Yan, H.S., Liu, J.S., Liu, P., Fan, A.N., Zhang, Z.L. (2020) Discussion on Corrosion and Anticorrosion Technology of Pipeline Equipment. J. Petro \& Chemical Equipment, 23(06): 113-116. 